\title{
Relationships among sport-products self-congnuence, product love, product trust, and purchase behavior of sports-for-all club members
}

\author{
Chae-Man Na* \\ Kyung Dong University
}

\begin{abstract}
[Purpose] The purpose of this study was to analyze the relationships among sport-products self-congruence, product love, product trust, and purchase behavior of sports-for-all club members through structural equation model analysis. [Methods] A survey was conducted targetting 227, men \& women in their twenties who are members of MTB, Tennis, Badminton, Golf in at the 8 in Seoul metropolitan area. For sampling method, convenience sampling method was used, while the questionnaire was self-administered. In an effort to verify the proposed structural model, this study used IBM SPSSWIN Ver. 21.0 and AMOS 18.0. [Results] First, actual self-congruence has positive influence on the product love. Second, ideal self-congruence didn't have positive influence on the product love. Third, social self-congruence has positive influence on the product love. Fourth, product love has positive influence on the product trust. Fifth, product trust has positive influence on the positive word-of-mouth. Sixth, product trust has positive influence on the repurchase intention. Seventh, product trust has positive influence on the attitudinal loyalty.
\end{abstract}

Key words: actual self-congruence, ideal self-congruence, social self-congruence, product love, product trust, positive word-of-mouth, repurchase intention, attitudinal loyalty

\section{서 론}

\section{연구의 필요성}

최근 여가시간의 확대와 국민소득증대 그리고 건강한 삶의 옥구로 인하여 스포츠참여 인구가 지속적으로 증가 하고 있다(Ministry of Culture Sports and Tourism, 2016). 스포츠참여는 단순히 건강관리 목적에서 벗어나 가족 중심의 산악캠핑이나 오토캠핑 활동은 물론 사회적 으로 다양한 스포츠 종목으로 그 범위가 확대되고 있다. 이러한 스포츠활동 인구의 증가는 스포츠 제품의 소비를

논문 투고일 : 2019. 09. 30.

논문 수정일 : 2019. 11. 04.

게재 확정일 : 2019. 12. 19.

* 교신저자 : 나채만(chaeman007@ naver.com).
증가시키고 있으며, 특히 소비자의 라이프스타일의 빠른 변화와 다양한 욕구를 만족시키기 위해 스포츠 제품은 다 양화 및 첨단화로 전개되어 스포츠 시장환경은 급격하게 변화하고 있다(Lee \& Jung, 2015). 하지만 제품의 다양 성은 소비자의 선택권을 확대했지만, 구매의사결정 과정 은 더욱 복잡해지고, 집단의 세분화 및 특성이 다양해 지 고 있어 소비자의 욕구를 충족시키는 것은 더욱 어려워지 고 있다(Yeh, Wang, \& Yieh, 2016). 이에 따라 소비자 들이 무엇을 토대로 제품을 선택하고 제품과의 관계를 구 축하는지 이해하는 것은 기업 측면에서 소비자와 제품 관 계를 안정적으로 유지 - 발전시키는 전략이 될 것이다.

소비자는 특정 브랜드가 가지고 있는 이미지와 같은 상징적 의미를 소비하기 위해 구매의사결정을 한다 (Sirgy \& Su, 2000). 즉 소비자는 자신의 이미지와 일치 하는 이미지를 지닌 제품이나 서비스를 구매할 가능성이 
상대적으로 높은데 이를 자아일시성이론(theory of self-congruity)이라 한다. 자아일치성은 소비자의 자아 이미지와 제품이미지 간 유사성의 정도를 의미한다. 이러 한 자아일치성을 소비자-제품 관계에서 중요한 결정요인 으로 간주하는 이유는 소비자들은 많은 제품 정보 중에서 자신의 자아이미지와 일치하는 정보를 더 잘 기억하고 자 아이미지와 일치하는 제품을 더욱 선호하고 그렇지 않은 제품을 회피하는 경향이 있기 때문이다(Sirgy, Rahtz, Cicic, \& Underwood, 2000). 이처럼 소비자가 특정 제 품을 선택하는 것은 자아개념의 표출이며, 특정 제품이 가진 차별적 이미지는 소비자들에게 다양한 유형의 자아 를 표현하는 데 도움을 주는 주요 수단이 된다(Johar, Sengupta \& Aaker, 2005). 따라서 소비자들이 추구하 는 자아이미지와 스포츠제품의 이미지 간의 자아일치성 을 고려하는 것은 기업의 제품이미지를 구축하기 위한 마 케팅전략에 유용한 시사점을 제공할 수 있을 것이다.

소비자행동 분야에서 브랜드와 고객 관계를 형성하는 정서적 경험을 설명하기 위해 브랜드사랑의 개념이 도입 되었다(Ahn \& Lee, 2017). 브랜드사랑은 소비자가 특 정 브랜드에 대해 강한 충성도를 형성하는 데 있어 핵심 적인 감정유형으로 특정 브랜드에 대해 갖는 열정적인 감 정적 애착과 긍정적 감정이 결합한 것으로 정의된다 (Ahn \& Lee, 2013). 소비자는 특정 브랜드에 대해 긍정 적인 태도를 형성해도 그 브랜드에 대한 애착이나 사랑을 경험하는 수준에 이르지 않을 수 있다는 점에서 브랜드태 도, 브랜드애착 개념과는 구분되는 개념이다(Carroll \& Ahuvia, 2006).

선행연구에서 소비자는 특정 스포츠 스타 브랜드에 대해 높은 자아 연관성을 갖게 되면 그 브랜드와의 관계를 유지 하며, 소비자-스타 브랜드 관계의 강화는 정서적 브랜드애 착을 기반으로 스타브랜드에 대한 사랑의 감정을 경험하게 된다고 하였다(Albert, Merunka \& Valette-Florence, 2008). 또한, Hwang \& Kandampully(2012)는 소비자 자아-브랜드이미지 일치성이 높은 브랜드가 그렇지 않은 브랜드에 비교해 브랜드사랑을 경험할 가능성이 더 크다 고 하였으며, Ahn \& Lee(2017)은 소비자가 지각하는 실제적, 이상적, 사회적 자아일치성 모두 브랜드사랑에 통계적으로 유의미한 영향을 미친다고 보고하고 있다. 이 처럼 소비자들은 자아일치성이 높은 브랜드에 대해 강력
한 감정적, 태도적, 행동적 반응을 보이며 (Carroll \& Ahurvia, 2006), 특정 브랜드가 소비자 자아의 일부분 으로 통합되었을 때 소비자는 그 브랜드에 대해 사랑의 감정을 경험하게 됨에도 불구하고(Ahurvia, 1993) 소비 자와 제품/브랜드와의 자아일치성과 사랑과의 관계를 밝 힌 연구는 미비한 실정이다. 특히 소비자 자아이미지와 스포츠제품이미지 간의 유대관계인 자아일치성과 스포 츠제품에 대해 만족한 소비자가 갖는 열정적인 감정적 애 착의 정도인 제품사랑과의 관계를 밝힌 연구는 찾아보기 힘들다.

Hwang \& Kandampully(2012)는 자아이미지일치성 과 브랜드사랑과 충성도와의 관계를 밝히고 있지만, 자아 이미지일치성을 단일차원으로 구성하여 자아이미지일치 성의 다양한 구성요인과 사랑과의 관계를 고려하지 않았 다. Ahn \& Lee(2017)의 연구에서는 스포츠스타 속성과 자아일치성 유형이 스포츠스타 브랜드사랑과 소비자 행 복과의 영향 관계를 처음으로 확인한 것에 의의를 두고 있지만, 구매행동과의 관계를 검증하지 않았다. 한편 Cheon \& Kim(2011)은 브랜드사랑의 선행변수로 친밀 감, 열정 및 몰입과의 관계와 브랜드사랑과 브랜드충성도 및 구전과의 검증을 통해서 소비자-브랜드 관계의 구매 후 행동 및 장기적인 관계를 설명하고자 하였으나, 브랜 드사랑을 결정하는 요인으로 친밀감, 열정 및 몰입 등의 감정적인 요인과의 관계에 초점을 두어 브랜드사랑의 원 인을 설명하는 데 한계를 보인다. 따라서 이 연구에서는 선행연구가 지닌 한계점을 고려하여 스포츠소비자의 자 아일치성을 실제적 자아일치성, 이성적 자아일치성 및 사 회적 자아일치성 요인으로 구성하여 제품사랑과의 관계 를 살펴보고, 제품사랑이 제품신뢰로 전이되어 궁극적으 로 구매행동 요인인 긍정적구전, 재구매의도 및 태도적충 성도에 영향을 미치는지 논의한다는 것에서 선행연구와 차별화할 수 있다.

신뢰와 충성도는 상호관계유지를 위한 노력을 촉진시 키는 역할을 하며, 환경의 불확실성을 감소시키는 중요한 인과관계를 갖는 개념이다(Morgan \& Hunt, 1994). Solomon(2002)은 개인에서 개인으로 전달되는 제품 정 보인 구전은 아는 사람으로부터 얻는 것이므로 공식적인 마케팅 경로를 통해 얻는 추천보다는 더욱 가치가 있고 신뢰할 수 있다(Park, 2015). 재구매의도는 행동적 성향이 
강한 특성이 있어 직접적인 소비로 이어지는 재구매행동 과 높은 연관성이 있다. 특히 제품 이용 후에 신뢰가 형성 된 고객은 향후 실제적인 재구매행동으로 이어질 가능성 이 크다(Han, 2017). 결과적으로 제품신뢰는 관계마케 팅 관점에서 볼 때 기업과 고객 간의 관계를 장기적으로 발전할 수 있게 하는 중요한 요인이 된다(Hong, 2014).

기업은 소비자들이 제품의 품질과 성능이 우수하거나 가격이 상대적으로 저렴한 제품을 선호하고 재구매하기 보다는 소비자와 제품 간의 감성적 유대관계를 구축함으 로써 제품에 대한 존경과 사랑이 중요하다는 것을 인식하 고 이를 위한 마케팅 노력을 하고 있다(Ahn \& Lee, 2013). 또한, 기술의 발전으로 기업 간의 제품품질 차이 가 감소하면서 더욱 치열한 시장환경에서 소비자의 구매 행동을 이해하는 것은 매우 중요하며, 소비자와 스포츠제 품 간의 개인적인 유대관계인 자아일치성 형성과정에서 느끼는 사랑의 감정이 신뢰를 통해서 스포츠제품에 대한 장기적인 구매행동과의 관계를 검증하는 것은 기업의 마 케팅 커뮤니케이션전략에 유용한 시사점을 제공할 수 있 을 것이다. 따라서 이 연구의 목적은 생활체육 동호인들 을 대상으로 스포츠제품과의 자아일치성 요인과 제품사 랑, 제품신뢰 및 구매행동과의 관계를 구조방정식모형분 석을 통해 규명하는 것이다. 구체적으로 첫째, 자아일치 성 요인을 실제적 자아일치성, 이상적 자아일치성 및 사 회적 자아일치성으로 구분하여 제품사랑과의 관계를 살 펴볼 것이다. 이를 통해 기업의 소비자-스포츠제품 관계 구축에 필요한 마케팅 커뮤니케이션 전략을 제공할 수 있 을 것이다. 둘째, 제품사랑과 제품신뢰와의 관계를 살펴 볼 것이다. 이러한 결과는 제품사랑이 소비자-스포츠제 품 관계를 유지할 수 있는 제품신뢰의 중요한 선행변수가 되는지 확인하여 스포츠기업의 관계마케팅 전략에 필요 한 시사점을 제시할 것이다. 셋째, 제품신뢰와 구매행동 과의 관계를 살펴볼 것이다. 이러한 결과는 복잡해진 의 사결정과정에서 소비자심리와 행동을 예측하기 위한 효 율적인 마케팅전략을 제시할 수 있을 것이다.

\section{연구모형 및 가설}

\section{자아일치성과 제품사랑과의 관계}

자아일치성은 소비자의 자아이미지와 제품이미지의
일치로 정의하며(Sirgy, Johar, Samli, \& Claiborne, 1991), 소비자들은 자아일치성이 높은 브랜드에 대해서 강력한 감정적, 태도적, 행동적 반응을 보인다(Carroll $\&$ Ahuvia, 2006). 즉 소비자-브랜드 관계의 강화는 소 비자의 정서적 브랜드애착을 토대로 브랜드에 대한 사랑 의 감정을 경험하게 된다(Albert et al., 2008). 선행연 구에서 자아일치성과 사랑과의 관계를 검증한 연구에서 자아일치성을 높게 지각할수록 브랜드사랑 정도가 증가 한다고 하였다. Hwang \& Kandampully(2012)는 소비 자 자아-브랜드이미지 일치성이 높은 브랜드가 그렇지 않은 브랜드에 비교해 브랜드사랑을 경험할 가능성이 더 크다고 하였으며, Ahn \& Lee(2017)은 소비자가 지각하 는 실제적, 이상적, 사회적 자아일치성 모두 브랜드사랑 에 통계적으로 유의미한 영향을 미친다고 보고하였다. 또 한, Kim et al. (2014)은 실제적 일치성과 사회적 일치성 이 브랜드사랑에 정 $(+)$ 의 영향을 미친다고 하였고, $\mathrm{Ahn}$ $\&$ Lee(2013)의 연구에서도 실제적 자아이미지 일치성 과 사회적 자아이미지 일치성이 브랜드사랑에 긍정적인 영향을 미친다고 보고하고 있다. 이와 같은 선행연구 결 과를 통해서 이 연구에서는 생활체육 동호인들의 자아일 치성 요인과 제품사랑과의 관계는 매우 유의미한 영향 관 계가 있을 것으로 판단된다. 따라서 다음과 같은 가설을 설정하였다.

$\mathrm{H} 1$ : 실제적 자아일치성은 제품사랑에 긍정적인 영향 을 미칠 것이다.

$\mathrm{H} 2$ : 이상적 자아일치성은 제품사랑에 긍정적인 영향 을 미칠 것이다.

$\mathrm{H} 3$ : 사회적 자아일치성은 제품사랑에 긍정적인 영향 을 미칠 것이다.

\section{제품사랑과 제품신뢰와의 관계}

소비의 감성화가 진행되고 마케팅 경쟁이 심화하면서 제품/브랜드 관리의 목표가 감성적 교류를 바탕으로 한 장기적 관계유지가 되고 있으며, 사랑의 개념이 제품/브 랜드에서도 느낄 수 있는 최상의 감정이 되고 있다 (Park, 2015). 이는 관계마케팅에 대한 중요성이 강조되 고 애착, 신뢰, 몰입 등의 정서적 개념이 연구되면서 소비 자-브랜드 관계에서 사랑의 역할에 관한 관심이 점차 높 아지게 되었다(Albert et al., 2008). 또한, 연구자들은 
브랜드신뢰를 소비자-브랜드 관계를 장기간 유지할 수 있게 하는 중요한 변수로 보고 관계마케팅 개념을 소비자 -브랜드 관계에 적용하고 기업의 관계마케팅에서 신뢰이 론을 발전시켰다(Reichheld, \& Schefter, 2000). 따라 서 소비자-브랜드 관계에서 사랑과 신뢰는 깊은 관련이 있을 것이다. Regan, Kocan, \& Whitlock(1998)은 신 뢰는 브랜드에 대한 사랑, 열정 그리고 긍정적인 평가와 감정의 결과로 간주하였으며, Loureiro, Ruediger \& Demetris (2012)는 브랜드사랑은 신뢰를 강화하고 향후 해당 브랜드와의 신뢰를 지속시키는 데 영향을 미친다고 보고하였다. 또한 Park(2015)은 브랜드사랑이 브랜드신 뢰에 긍정적인 영향을 미친다고 하였다. 이러한 선행연구 를 바탕으로 생활체육 동호인들의 스포츠제품에 대한 사 랑이 클수록 제품에 대해 믿음은 높아질 것으로 기대할 수 있다. 따라서 다음과 같은 가설을 설정하였다.

$\mathrm{H} 4$ : 제품사랑은 제품신뢰에 긍정적인 영향을 미칠 것 이다.

\section{제품신뢰와 구매행동과의 관계}

신뢰는 소비자행동에 직·간접적인 영향을 미치는 결 정요인 중 하나이다(Sirdeshmukh, Singh \& Sabol, 2002). 특히 브랜드를 통한 신뢰는 기업과 소비자 간의 관계에 있어서 해당 브랜드를 안심하게 선택하고 사용할 수 있는 커뮤니케이션 촉진 도구라 할 수 있다. 또한, 신 뢰는 교환관계에서 상대방이 의무를 다할 것이라는 믿음 또는 기대로 정의하고 있으며, 소비자가 구매과정에서 구 축한 신뢰는 해당 대상에 대한 긍정적인 평가와 행동으로 전이된다(Kramer, 1999). 이와 관련된 선행연구에서 Morgan \& Hunt(1994), Gabarino \& Johnson(1999) 은 신뢰가 재방문의도 및 구매충성도에 직간접적 영향을 미친다고 하였으며, Sirdesmukh et al.(2002)의 연구에 서도 신뢰가 제품의 반복구매를 의미하는 충성도에 유의 미한 영향을 미침으로써 충성도의 결정요인 중 하나가 된 다고 하였다. Chaudhuri \& Holbrook(2001)은 충성도 는 신뢰에 의해서 발생하는 가치 있고 중요한 관계를 유 지하는 프로세스의 한 부분이며, 교환관계에 의하여 신뢰 와 충성도는 밀접한 관계가 있다고 하였다. 또한, 브랜드 신뢰성은 소비자들의 충성도를 지속해서 유지 및 강화하 는 선행변수로써 기존의 연구결과들은 브랜드신뢰성이
브랜드충성도를 강화하는 중요한 선행변수가 될 수 있으 며(Hyoung, 2011), 많은 연구에서 신뢰가 충성도에 긍 정적인 영향을 미친다고 보고하고 있다(Tsiotsou, 2013; Kim, 2015). 따라서 생활체육 동호인들은 자신이 좋아하는 제품에 대한 신뢰도가 높을수록 긍정적구전과 재구매의도 및 태도적충성도는 향상될 것으로 기대할 수 있다. 따라서 다음과 같은 가설을 설정하였다.

$\mathrm{H} 5$ : 제품신뢰는 긍정적구전에 긍정적인 영향을 미칠 것이다.

$\mathrm{H} 6$ : 제품신뢰는 재구매의도에 긍정적인 영향을 미칠 것이다.

$\mathrm{H} 7$ : 제품신뢰는 태도적충성도에 긍정적인 영향을 미 칠 것이다.

〈Fig 1〉은 이론적 배경에서 설정한 총 7개의 가설을 바 탕으로 이 연구의 모형을 보여주고 있다.

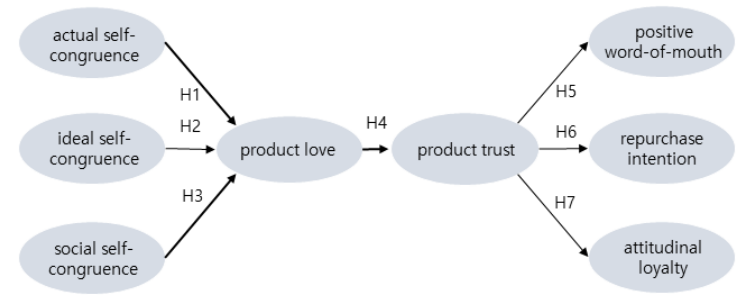

Figure 1. The Hypothesized Model

\section{연구방법}

\section{표본 및 자료수집}

이 연구에서는 수도권 지역의 생활체육 동호회 중 가 입 회원이 50명 이상인 MTB, 테니스, 배드민턴, 골프 동 호회 각각 2개소씩 총 8개소에서 성인 남녀 30명씩 총 240 명을 대상으로 하였다. 조사방법은 사전에 설문조사 를 허락한 동호회에 우편발송-방문회수법을 이용하였으 며, 설문지 작성은 자기기입식으로 하였다. 조사기간은 
2018년 05월01일 05월30일 까지 실시하였으며, 불성 실하게 작성한 13 부를 제외한 227 부가 최종 통계분석에 이용되었다.

설문조사 대상의 제품은 동호인들에게 친숙하고 가시 성이 높은 스포츠와 관련된 의류 및 운동화이다. 이는 최 근 1년간 구매한 스포츠용품 종류에서 스포츠의류가 $73.9 \%$, 스포츠신발류 $73.7 \%$, 라켓류 $5.3 \%$, 구기류 $4.7 \%$ 등의 순으로 나타났기 때문이다(Ministry of Culture Sports and Tourism, 2018). 설문응답자는 스 포츠의류나 운동화에 대해서 자신의 이미지를 가장 잘 반 영하고 있는 제품을 연상하며 응답하도록 하였다. 이 연 구에서 특정 브랜드를 선정하지 않은 이유는 소비자들의 라이프스타일 변화와 자아표현의 가치를 높이는 브랜드 가 다양하므로 특정 브랜드로 한정하지 않고 외적타당성 을 높일 수 있도록 하였다. 스포츠동호인들의 일반적인 내용은〈Table 1〉과 같다.

Table 1. Characteristics of respondents

\begin{tabular}{cccc}
\hline \hline Attributes & Content & Number & Frequency $(\%)$ \\
\hline \multirow{3}{*}{ Gender } & Male & 146 & 64.3 \\
\cline { 2 - 4 } & Female & 81 & 35.7 \\
\hline \multirow{4}{*}{ Age } & Twenties & 12 & 5.3 \\
\cline { 2 - 4 } & Thirties & 72 & 31.7 \\
\cline { 2 - 4 } & Forties & 87 & 38.3 \\
\cline { 2 - 4 } & Fifties & 51 & 22.5 \\
\cline { 2 - 4 } Average of Age & over Sixties & 5 & 2.2 \\
\hline \multirow{5}{*}{ Occupation } & & 43 & \\
\cline { 2 - 4 } & Employed & 120 & 52.9 \\
\cline { 2 - 4 } & Own business & 56 & 24.7 \\
\cline { 2 - 4 } & Others & 21 & 9.3 \\
\cline { 2 - 4 } & House worker & 16 & 7.0 \\
\cline { 2 - 4 } & Not employed & 14 & 2.6 \\
\hline \hline
\end{tabular}

\section{구성개념의 조작적 정의 및 측정}

이 연구에서는 스포츠 제품사랑의 주요 결정요인으로 소비자가 인식하고 추구하는 자아와 스포츠제품의 상징 적 의미 및 이미지가 서로 얼마나 강하게 연결되어 있는 지 소비자 자아이미지-스포츠제품이미지 간의 유대관계 인 자아일치성을 제안한다.

자아일치성 유형 중 실제적 자아일치성 (actual self- congruence)은 개인이 지닌 이미지만을 나타내는 실제적 자아와 스포츠제품 이미지 간의 일치 정도로 정의하였고, 이상적 자아일치성 (ideal self-congruence)은 개인이 추 구하는 이상적 자아와 스포츠제품 이미지 간의 일치 정도 를 의미하며, 사회적 자아일치성 (socialself-congruence) 은 주변 사람들이 실제로 자신을 어떻게 바라볼 것인가에 대한 사회적 자아와 스포츠제품 이미지 간의 일치 정도를 의미한다. 이를 측정하기 위해 Sirgy et al.(1997), Kressmann et al.(2006), Choi \& Cho(2016)의 연구 에서 사용한 문항을 각각 4 문항씩 총 12 문항으로 구성하 였다.

제품사랑(product love)은 특정 제품에 대한 열정적인 감정적 애착의 정도라 정의하고, Batra, Ahuvia, \& Bagozzi(2012)와 Carroll \& Ahuvia(2006)의 연구를 바탕으로 4문항으로 구성하였다.

제품신뢰(product trust)는 자신이 이용하는 제품에 대한 전반적인 믿음 정도를 의미하며, Chaudhuri \& Holbrook(2001)의 측정항목을 활용하여 Hyoung(2011) 이 사용한 4문항으로 구성하였다.

구매행동 요인 중 긍정적구전은 이용한 제품을 다른 사람들에게 긍정적으로 이야기할 정도를 의미하며, Carroll \& Ahuvia(2006)의 연구를 바탕으로 Park(2015) 이 이용한 4 문항으로 구성하였다.

재구매의도는 이용한 제품을 다시 이용하고자 하는 의 지로 정의하였고, Bower \& Tumer(2001), Coyle \& Thorson(2001)의 측정항목을 참고하여 Choi \& Choi(2009)이 활용한 4문항으로 구성하였다.

태도적충성도는 특정 제품에 대한 감정적 애착 정도를 의미하며, Rauyruen \& Miller(2007), Chiou \& Droge(2006), Min \& Choi(2018)가 사용한 것을 활용 하여 4 문항으로 구성하였다. 측정항목들은 5 단계 Likert 척도를 사용하여 1 (전혀 아니다) 5 (매우 그렇다)까지로 측정하였다. 또한, 조사대상의 특성을 살펴보기 위해서 성별, 연령, 직업 등 3 문항을 포함하였다.

\section{자료분석}

이 연구의 자료분석은 SPSSWIN Ver. 21.0과 AMOS 18.0 을 활용하였다. 조사대상의 특성을 분석하기 위해 
Table 2. Confirmatory Factor Analysis and Reliabilities

\begin{tabular}{|c|c|c|c|c|c|c|c|}
\hline Factors & Items & $\mathrm{SC}$ & SE & t-value & $\alpha$ & $\mathrm{CR}$ & AVE \\
\hline \multirow{4}{*}{$\begin{array}{l}\text { actual self- } \\
\text { congruence }\end{array}$} & This product expresses my actual image well. & .701 & .421 & - & \multirow{4}{*}{.734} & \multirow{4}{*}{.759} & \multirow{4}{*}{.512} \\
\hline & This product reflects my actual image well.* & - & - & - & & & \\
\hline & This product matches my actual image. & .667 & .467 & 8.377 & & & \\
\hline & My actual image is similar to those who like this product. & .709 & .482 & 8.764 & & & \\
\hline \multirow{4}{*}{$\begin{array}{l}\text { ideal self- } \\
\text { congruence }\end{array}$} & This product expresses my ideal image. & .693 & .535 & - & \multirow{4}{*}{.841} & \multirow{4}{*}{.882} & \multirow{4}{*}{.715} \\
\hline & This product reflects my ideal image.* & - & - & - & & & \\
\hline & This product matches my ideal image. & .876 & .171 & 11.390 & & & \\
\hline & My ideal image is similar to those who like this product. & .863 & .202 & 11.319 & & & \\
\hline \multirow{4}{*}{$\begin{array}{l}\text { social self- } \\
\text { congruence }\end{array}$} & This product makes my image stand out in social life. & .799 & .291 & - & \multirow{4}{*}{.915} & \multirow{4}{*}{.930} & \multirow{4}{*}{.769} \\
\hline & This product shows my social position. & .828 & .301 & 14.125 & & & \\
\hline & This product has a positive effect on people's view. & .911 & .137 & 16.087 & & & \\
\hline & This product has a good influence on my social evaluation. & .894 & .156 & 15.690 & & & \\
\hline \multirow{4}{*}{$\begin{array}{l}\text { product } \\
\text { love }\end{array}$} & Love this product. & .806 & .550 & - & \multirow{4}{*}{.886} & \multirow{4}{*}{.840} & \multirow{4}{*}{.570} \\
\hline & There is a passionate feeling about this product. & .723 & .780 & 11.634 & & & \\
\hline & This product makes me feel good. & .916 & .295 & 15.213 & & & \\
\hline & This product makes me happy. & .878 & .472 & 12.413 & & & \\
\hline \multirow{4}{*}{$\begin{array}{c}\text { product } \\
\text { trust }\end{array}$} & I can use this product safely.* & - & - & - & \multirow{4}{*}{.907} & \multirow{4}{*}{.925} & \multirow{4}{*}{.804} \\
\hline & I don't think we'll lose any money if we buy this product & .881 & .176 & - & & & \\
\hline & This product is reliable. & .902 & .146 & 18.722 & & & \\
\hline & This product is reliable. & .844 & .239 & 16.733 & & & \\
\hline \multirow{4}{*}{$\begin{array}{c}\text { positive } \\
\text { word-of-mouth }\end{array}$} & I will recommend this product to many people.* & - & - & - & \multirow{4}{*}{.869} & \multirow{4}{*}{.860} & \multirow{4}{*}{.674} \\
\hline & I will talk about this product to my friends. & .764 & .455 & - & & & \\
\hline & I will try to say good things about this product. & .893 & .217 & 13.595 & & & \\
\hline & I'll let you know positively about this product. & .846 & .344 & 13.031 & & & \\
\hline \multirow{4}{*}{$\begin{array}{l}\text { repurchase } \\
\text { intention }\end{array}$} & I am willing to purchase this product again. & .904 & .181 & - & \multirow{4}{*}{.943} & \multirow{4}{*}{.944} & \multirow{4}{*}{.850} \\
\hline & Will buy this product again. & .961 & .076 & 24.953 & & & \\
\hline & I plan to buy this product continuously. & .900 & .194 & 21.423 & & & \\
\hline & I will take an active action to purchase this product again.* & - & - & - & & & \\
\hline & I have a good feeling about this product. & .902 & .128 & - & & & \\
\hline attitudinal & I have a love for this product. & .891 & .153 & 18.691 & 904 & 921 & 746 \\
\hline & I have a favorable attitude to this product. & .808 & .256 & 15.754 & .904 & .921 & .140 \\
\hline & I think the current product is better than the others. & .702 & .398 & 12.431 & & & \\
\hline Fit: $\chi^{2}=493.18$ & $(d f=294, p<.001), \mathrm{GFI}=.868, \mathrm{CFI}=.956, \mathrm{TLI}=.948, \mathrm{RMR}=.0^{\prime}$ & .055 & & & & & \\
\hline
\end{tabular}

빈도분석을 하였고, 내적일관성신뢰도 검사를 위해 Cronbach's $\alpha$ 검사를 하였다. 판별타당성을 검증하기 위 해 상관관계분석, 확인적 요인분석을 이용하여 잠재변수 를 생성하여 수렴타당성과 판별타당성을 검증하였다. 또 한, 모형의 적합도 및 개별가설을 검증하기 위해 구조방 정식모형분석을 하였다.

\section{연구결과}

\section{구성개념의 신뢰성 및 타당성 분석}

이 연구에서 사용된 측정항목들은 기존 연구들에서 신 뢰성과 타당성을 인정받은 항목들로 구성하였다. 각 개념 
의 내적일관성을 살펴보기 위해 Cronbach's $\alpha$ 값을 활용 하여 신뢰성을 검토한 결과, .734 .943 사이로 나타나 .7을 상회하여 측정항목의 신뢰성이 확보되었다 (Nunnally \& Bernstein, 1994).

실증분석을 위한 가설검증 이전에 측정항목들의 확인 적요인분석을 통해 차원성을 평가하고 연구모형의 타당 성 및 신뢰도를 검증했다. 측정항목의 타당성을 분석하기 위해 단일차원성이 확인된 8개의 구성개념을 모두 포함 하는 측정모형에 대해 확인적요인분석을 실시한 결과, 측 정모형에 대한 적합도 지수는 $\chi^{2}=493.187, d f=294$, $p \nmid .001, \mathrm{GFI}=.868, \mathrm{CFI}=.956, \mathrm{TLI}=.948, \mathrm{RMR}=.070$, RMSEA $=.055$ 로 Hair, Black, Babin, Anderson, \& Tatham(2009)이 제시한 적합도 기준을 충족시켰다 (GFI, CFI, TLI .8 .9이상, RMR, RMSEA .05 .08 이하). 구조방정식 모형에서 사용되는 적합도는 절대적 기준이기보다는 상대적인 지표로 통합적인 관점에서 다 른 지표들과 함께 판단한다. 이 과정에서 실제적자아일치 성 2 , 이상적자아일치성 2 , 제품신뢰 1 , 긍정적구전 1 , 재구 매의도4 문항 등이 각각의 개념을 측정하는 문항들과 수 렴되지 못해 제거되었다.

확인적요인분석을 실시하고 측정모형의 집중타당성과 판별타당성을 분석하였다. 잠재요인의 집중타당성을 평 가하는 방법은 표준화 요인적재량의 크기, 평균분산추출 값 $(\mathrm{AVE})$, 잠재요인의 신뢰도 값의 크기 $(\mathrm{CR})$ 등이 있다. 표준화 요인적재량이 .7이상을 상회하지 못하는 항목이 존재하지만, 통계적으로 유의하게 나타났으며, AVE값은
$.512 \sim .850$ 으로 .5 이상이며, $\mathrm{CR}$ 값은 .759 .944로 .7 이상을 충족하고 있으므로 측정모형의 집중타당성이 존 재하는 것으로 평가될 수 있다(Fornell \& Larcker, 1981). 자세한 내용은 〈Table 2〉와 같다.

판별타당성을 측정하기 위해 각 잠재요인의 $\mathrm{AVE}$ 값이 상관계수의 제곱값을 상회할 때 판별타당성이 확보된다 고 하였다(Anderson \& Gerbing, 1988). 분석결과, 상 관계수의 제곱값은 .003 .420(.1782 .6482)으로 가 장 큰 상관계수의 제곱값이 .420이고, 가장 작은 AVE값 이 .512로 상관계수 제곱값들이 해당개념의 AVE값을 넘 지 않아 판별타당성을 확보한 것으로 판단되었다. 자세한 내용은 〈표 3〉과 같다. 또한, 모든 구성개념의 상관계수 수치가 기준치인 .8 보다 낮게 나타남으로써 다중공선성 은 존재하지 않는 것으로 입증되었다.

\section{연구가설 검증}

제시한 연구모형과 연구가설에 대한 검증을 위해 최대 우도법 (maximum likelihood method)을 적용하여 모형 의 적합도와 경로계수를 파악했다. 연구모형의 적합도를 검증결과, $\chi^{2}=448.925, d f=284, p<.001, \mathrm{GFI}=.874$, $\mathrm{CFI}=.961, \mathrm{TLI}=.955, \mathrm{RMR}=.068, \mathrm{RMSEA}=.051$ 로 권장 기준을 충족하여 모형은 안정적인 것으로 나타났다. 따라서 가설검증을 실시하기에 적절한 수준이라고 판단 하였다. 가설검증결과를 살펴보면, '가설1의 실제적자아 일치성은 제품사랑에 긍정적인 영향을 미치는 것이다.'는

Table 3. Correlations among Variables

\begin{tabular}{|c|c|c|c|c|c|c|c|c|}
\hline Factors & $\begin{array}{l}\text { actual self- } \\
\text { congruence }\end{array}$ & $\begin{array}{l}\text { ideal self- } \\
\text { congruence }\end{array}$ & $\begin{array}{l}\text { social self- } \\
\text { congruence }\end{array}$ & $\begin{array}{l}\text { product } \\
\text { love }\end{array}$ & $\begin{array}{l}\text { product } \\
\text { trust }\end{array}$ & $\begin{array}{c}\text { positive } \\
\text { word-of-mouth }\end{array}$ & $\begin{array}{c}\text { repurchase } \\
\text { intention }\end{array}$ & $\begin{array}{c}\text { attitudinal } \\
\text { loyalty }\end{array}$ \\
\hline actual self-congruence & 1 & & & & & & & \\
\hline ideal self-congruence & $.643^{* *}$ & 1 & & & & & & \\
\hline social self-congruence & $.624 * *$ & $.432 * *$ & 1 & & & & & \\
\hline product love & $.342 * *$ & $.178^{*}$ & $.350 * *$ & 1 & & & & \\
\hline product trust & $.648 * *$ & $.517 * *$ & $.581 * *$ & $.520 * *$ & 1 & & & \\
\hline positive word-of-mouth & $.527 * *$ & $.439 * *$ & $.506^{* *}$ & $.345^{* *}$ & $.643 * *$ & 1 & & \\
\hline repurchase intention & $.455^{* *}$ & $.397 * *$ & $.474 * *$ & $.348^{* *}$ & $.489 * *$ & $.568^{* *}$ & 1 & \\
\hline attitudinal loyalty & $.382 * *$ & $.362 * *$ & $.431 * *$ & $.412 * *$ & $.517 * *$ & $.506^{* *}$ & $.644^{* *}$ & 1 \\
\hline
\end{tabular}


Table 4. Testing of the Proposed Hypotheses

\begin{tabular}{ccccccc}
\hline \hline Hypotheses & Paths & SC & SE & $t$ & $p$ & Acceptance \\
\hline H1 & actual self-congruence $\rightarrow$ product love & .296 & .111 & 2.681 & .007 & Acceptance \\
H2 & ideal self-congruence $\rightarrow$ product love & .132 & .072 & 1.837 & .066 & Rejected \\
H3 & social self-congruence $\rightarrow$ product love & .299 & .077 & 3.883 & .000 & Acceptance \\
H4 & product love $\rightarrow$ product trust & 1.377 & .208 & 6.633 & .000 & Acceptance \\
H5 & product trust $\rightarrow$ positive word-of-mouth & .695 & .073 & 9.477 & .000 & Acceptance \\
H6 & product trust $\rightarrow$ repurchase intention & .531 & .063 & 8.475 & .000 & Acceptance \\
H7 & product trust $\rightarrow$ attitudinal loyalty & .636 & .074 & 8.614 & .000 & Acceptance \\
\hline Fit: $\chi^{2}=448.925, d f=284, p<.001, \mathrm{GFI}=.874, \mathrm{CFI}=.961, \mathrm{TLI}=.955, \mathrm{RMR}=.068, \mathrm{RMSEA}=.051$ & & & & \\
\hline \hline$* * * p<.001, * * p<.01$ & & & & &
\end{tabular}

경로계수 $=.296, t=2.681$ 로 $p$ 〈.007로 통계적으로 유의 한 것으로 나타나 채택되었다. '가설2의 이상적자아일치 성은 제품사랑에 긍정적인 영향을 미치는 것이다.'는 경 로계수 $=.132, t=1.837$ 로 $p>$.066으로 통계적으로 유의 하지 않은 것으로 나타나 기각되었다. '가설3의 사회적자 아일치성은 제품사랑에 긍정적인 영향을 미치는 것이다.' 는 경로계수 $=.299, t=3.883$ 으로 $p 〈 .001$ 로 통계적으로 유의한 것으로 나타나 채택되었다. '가설 4 의 제품사랑은 제품신뢰에 긍정적인 영향을 미치는 것이다.'는 경로계수 $=1.377, t=6.633$ 으로 $p<.001$ 로 통계적으로 유의한 것 으로 나타나 채택되었다. '가설5의 제품신뢰는 긍정적구 전에 긍정적인 영향을 미치는 것이다.'는 경로계수 =.693, $t=9.477$ 로 $p$ 〈.001로 통계적으로 유의한 것으 로 나타나 채택되었다. '가설6의 제품신뢰에 재구매의도 에 긍정적인 영향을 미치는 것이다.'는 경로계수 $=.531$, $t=8.475$ 로 $p 〈 .001$ 로 통계적으로 유의한 것으로 나타나 채택되었다. '가설7의 제품신뢰는 태도적충성도에 긍정 적인 영향을 미치는 것이다.'는 경로계수 $=.636$, $t=8.614$ 로 $p<.001$ 로 통계적으로 유의한 것으로 나타나 채택되었다. 자세한 내용은 〈Fig 2〉와 같다.

\section{논의}

이 연구에서는 생활체육동호인들의 스포츠제품에 대 한 구매행동을 강화시키려는 자아일치성 요인에 주목하 고 제품사랑과 제품신뢰를 통해서 긍정적구전, 재구매의 도 및 태도적충성도와의 관계를 검증하였다. 실증분석 결

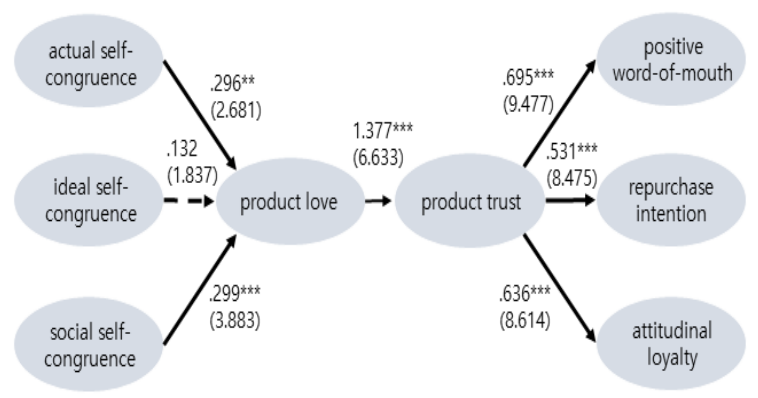

Note: Standardized coefficient/t-value/ $p<.01^{\star *}, p<.001^{\star * *}$

Figure 2. Estimates Final Structural Model

과는 다음과 같다. 첫째, 실제적자아일치성과 사회적자 아일치성은 제품사랑에 긍정적인 영향을 미치는 것으로 나타났다. 이는 스포츠제품의 개성 혹은 이미지와 동호인 들의 자아이미지 간의 일치 정도가 높을수록 제품사랑을 보다 강하게 경험한다는 것이다. 또한, 스포츠제품을 통 해서 자신의 이미지를 긍정적으로 높게 평가받을수록 제 품사랑도 높아진다는 것이다. 즉 제품사랑을 경험하는 데 있어 실제적자아일치성과 사회적자아일치성이 선행요인 이 된다는 것을 확인하였다. 하지만, 이상적자아일치성 은 제품사랑에 긍정적인 영향을 미치지 않았다. 이는 동 호인들이 추구하는 이상적자아이미지와 스포츠제품이미 지 간의 일치 정도가 높더라도 제품사랑에 긍정적인 영향 을 미치지 않는다는 것이다. 이는 Ahn \& Lee(2013)의 연구결과와 같은 맥락이다. 동호인들은 심리적으로 실제적 자아이미지와 일치되는 스포츠제품에 대해 강한 정서적 경험을 하게 된다고 하였다. 즉 미래의 자신을 표현하려는 
옥구보다 현재의 자신을 표현하려는 욕구가 더욱 구체적 이고 현실적이기 때문이다. Trope \& Liberman(2010) 의 해석수준이론(construal-level theory)에서 특정 대 상과 심리적 거리가 멀수록 대상에 대해 추상적 수준에서 개념화하고 심리적 거리가 가까울수록 구체적 수준에서 개념화하는 경향을 보인다고 하였다. 즉 실제적자아일치 성이 높은 제품에 심리적 거리가 가깝기 때문에 제품에 대해 정서적 경험을 하며, 강한 사랑의 감정을 느끼게 되 는 것이다. 또한, 이 연구에서는 사회적자아일치성이 제 품사랑에 가장 큰 영향을 미치는 것으로 나타났다. 이러 한 결과는 특정 준거집단의 특성이 잘 반영된 결과라 판 단된다. 즉 동호인들은 소속된 동호회와의 사회적 관계를 형성하게 되면서 자신의 이미지, 사회적 위치 및 평가 등 다른 사람들의 시각에 긍정적으로 어필하고자 한다. 이때 스포츠 제품을 통해서 주변 사람들에게 어필하면서 사회 적인 평가와 인정을 받고자 하는 것으로 판단된다. 시장 을 세분화하고 표적화할 때 마케팅 효율성을 증대시킬 수 있으므로 마케팅관리자는 스포츠소비자들의 개성과 이 미지 등의 개인적 측면과 사회적 측면의 상징적 요소를 파악하여 시장을 세분화하여 목표 고객에게 맞는 광고전 략 수행한다면 제품에 대한 사랑을 유도할 수 있을 것이 다. 둘째, 제품사랑은 제품신뢰에 긍정적인 영향을 미치 는 것으로 나타났다. 이러한 결과는 제품사랑이 제품신뢰 에 선행요인이 된다는 것이다. 선행연구에서 Loureiro et al. (2012)은 브랜드사랑은 신뢰를 강화하고 향후 해당 브랜드와의 신뢰를 지속시킨다고 하였다. 또한, $\operatorname{Park}(2015)$ 의 브랜드사랑이 브랜드신뢰에 긍정적인 영 향을 미친다는 연구결과가 뒷받침해 준다. 따라서 스포츠 제품이 동호인들에게 신뢰를 받기 위해서는 제품의 감정 적인 애착을 높여야 한다. 즉 마케팅관리자는 제품개발에 있어서 감정적 촉진요소를 활용하여 접 근하여야 하며, 제 품정보에 관한 메시지전달에도 정서적 유대감과 열정 등 을 고려하여야 할 것이다. 셋째, 제품신뢰는 긍정적구전, 재구매의도 및 태도적충성도에 긍정적인 영향을 미치는 것으로 나타났다. 이는 제품신뢰가 제품 구매의도에 긍정 적인 영향을 미친다는 연구(Cho \& Lee, 2015), 제품신 뢰도가 재구매의도와 구전효과에 긍정적인 영향을 미친 다는 연구(Hwang, Yoon, \& Kim, 2019)와 같은 결과이 다. 이러한 결과는 관계마케팅에서 소비자와 상호작용하
는 핵심개념인 신뢰가 소비자들의 구매행동을 지속적으 로 유지하고 강화시키는 중요한 원인이 된다는 것이다. 즉 스포츠제품 고객들의 복잡해진 구매행동을 예측하기 위한 효율적인 마케팅전략을 위해서는 고객이 기대하는 성능을 지속적으로 제공할 것이라는 믿음에서 비롯된다. 이를 위해서는 고객이 원하는 실용성과 상징적 욕구를 충 족시키는 것이 필요하다. 또한, 제품과의 친밀감을 높일 수 있는 사회적 공헌 활동을 적극적으로 하여 제품에 대 한 신뢰감을 높이는 것이 최근의 비즈니스 환경에서 경쟁 우위를 창출하고 유지하는 방법이며, 장기적인 기업 성장 확보에 매우 필요할 것이다(Yang, 2012). 마지막으로 전자 고객관리를 이용한 상품과 서비스를 다양한 채널로 제공함으로써 소비자와 제품 관계를 구축하기 위한 통합 적인 마케팅커뮤니케이션 전략이 필요하다.

\section{결 론}

\section{연구의 시사점}

이 연구에서는 생활체육동호인들의 스포츠제품에 대 한 자아일치성 요인 중 실제적자아일성과 사회적자아일 치성이 제품사랑과 제품신뢰를 통해서 긍정적구전, 재구 매의도 및 태도적충성도에 긍정적인 영향을 미친다는 것 을 확인하였다. 이를 통한 시사점은 다음과 같다. 첫째, 실제적자아일치성과 사회적자아일치성이 제품사랑을 강 화하는 중요한 선행요인이 된다는 것을 확인하였다. 따라 서 마케터는 스포츠동호인들의 실제적 자아와 사회적 자 아와 일치하는 제품의 개성과 이미지를 형성하도록 마케 팅전략을 수행하여야 한다는 것을 시사한다. 둘째, 제품 사랑은 제품신뢰로 전이된다는 것을 확인하였다. 이는 제 품에 대한 열정적 애착인 사랑이 소비자-제품 관계 구축 에서 신뢰를 강화할 수 있는 중요한 개념이 된다는 것을 시사한다. 셋째, 제품신뢰는 동호인들의 실제적인 구매 행동을 지속적으로 유지하고 강화시키는 중요한 원인이 된다는 것을 시사한다. 따라서 동호인들에게 제품에 대한 전문성과 진실성을 인정받을 수 있도록 하여 믿을 수 있 는 제품이미지를 형성하는 전략을 고려해야 할 것이다. 


\section{연구의 한계점}

이 연구에서는 다음과 같은 한계를 가지고 있다. 첫째, 이 연구에서는 수도권에 있는 MTB, 테니스, 배드민턴, 골프 종목의 생활체육 동호인을 대상으로 편의표본추출 법을 활용하여 자료를 수집하여 연구결과를 일반화하는 데 한계가 있다. 후속연구에서는 다양한 지역과 종목을 확대하여 외적타당성을 높여야 할 것이다. 둘째, 이 연구 에서는 다양한 변수들과의 관계를 고려하지 못했다는 한 계가 있다. 후속연구에서는 사랑의 선행요인이 될 수 있 는 제품에 대한 개성, 동일시, 이미지, 태도, 선호도, 자 아존중감 등 다양한 변수들과의 관계를 검증한다면 의미 있을 것이다. 셋째, 이 연구에서는 스포츠동호인들에게 고관여 제품인 스포츠의류와 운동화에 대해 강한 애착을 경험할 것으로 판단하였다. 후속연구에서는 저관여/고관 여 제품으로 구성하여 사랑과의 관계를 비교하는 것도 필 요할 것이다.

\section{참고문헌}

Ahn, K. H., \& Lee, J. H. (2013). The effect of consumer self-congruence and perceived product quality on the brand love. Journal of Consumer Studies, 24(4), 125-146.

Ahn, K. H., \& Lee, J. H. (2017). The influence of star brand image-consumer self congruence and star attributes on love for star brand and consumer happiness-based on sports star brand. The Korean Journal of Advertising, 28(1), 151-175.

Ahuvia, A. C. (1993). I love towards a unifying theory of love across diverse love objects. Ph.D. Dissertation, Northweatern University, Evanston, IL.

Albert, N., Merunka, D., \& Valette-Florence, P. (2008). When consumers love their brands: Exploring the concept and its dimensions. Journal of Business Research, 61(10), 1062-1075.

Anderson, J. C., \& Gerbing, D. W. (1988). Structural equation modeling in practice: A review and recommended two-step approach. Psychological Bulletin, 103(3), 411-423.

Batra, R., Ahuvia, A., \& Bagozzi, R. P. (2012). Brand love. Journal of Marketing, 76(2), 1-16.

Bower, J. A., \& Tumer, L. (2001). Effects of liking, brand name and price on purchase intention for branded, own label and economy line crisp snack foods. Journal of Sensory Studies, 16(1), 95-115.

Carroll, B. A., \& Ahuvia, A. C. (2006). Some antecedents and outcome of brand love. Marketing Letters, 17, 79-89.

Chaudhuri, A., \& Holbrook, M. B. (2001). The chain of effects from brand trust and brand affect to brand performance: The role of brand loyalty. Journal of Marketing, 65(2), 81-93.

Cheon, H. S., \& Kim, D. Y. (2011). The effect of brand love, brand management, and word-of-mouth on brand management. The e-Business Studies, 12(2), 199-227.

Chiou, J. S., \& Droge, C. (2006). Service quality, trust, specific asset investment, and expertise: Direct and indirect effects in a satisfaction-loyalty framework. Journal of the Academy of Marketing Science, 34, 613-627.

Cho, E. M., \& Lee, E. S. (2015). The effects of corporate social responsibility activities, social enterprise attitude, and reliability in the products of social enterprise on the purchase intention: Perspective of social enterpriser. Journal of CEO and Management Studies, 18(1), 69-98.

Choi, H. S., \& Cho, Y. H. (2016). The effects of self-congruity with wine brand on brand attitude and brand loyalty. Journal of Tourism Sciences, 40(4), 87-107.

Choi, J. Y., \& Choi, Y. S. (2009). Analysis of competitive effects of attitudes toward private brand and national brand on purchase intentions. Journal of Commodity Science and Technology, 27(4), 69-80.

Coyle, J. R., \& Thorson, E. (2001). The effects of progressive levels of interactivity and vividness in web marketing sites. Journal of Advertising, 30(3), 65-78.

Fornell, C., \& Larcker, D. F. (1981). Evaluation structural equation models with unobservable variables and measurement error. Journal of Marketing, 63(2), 70-87.

Garbarino, E., \& Johnson, M. S. (1999). The different roles of satisfaction, trust, and commitment in customer relationships. Journal of Marketing, 63(2), 70-87.

Hair, J. F., Black, W. C., Babin, B. J., Anderson, R. E., \& Tatham, R. L. (2009). Multivariate data analysis. 7th ed. Prentice-Hall International, Inc.

Han, J. S. (2017). Effects of brand image on purchase intention and brand loyalty: Focused on mediating role of the brand trust. Culinary Science \& Hospitality Research, 23(2), 135-145.

Hong, S. H. (2014). Antecedents and its consequence of local consumers trust in MNCs product: The moderating effect of 
global corporate citizenship. International Commerce and Information Review, 16(3), 357-380.

Hwang, J. S., Yoon, Y. J., \& Kim, H. J. (2019). The effects of product reliability on brand image, repurchase intention, and word-of-mouth in the context of home meal replacement: The moderating role of the manufacturer type. International Journal of Tourism and Hospitality Research, 33(1), 217-226.

Hwang, J., \& Kandampully, J. (2012). The role of emotional aspects in younger consumer brand relationships. Journal of Product and Brand Management, 21(2), 98-108.

Hyoung, Y. H. (2011). The effect of self-congruity on the brand loyalty. Journal of Industrial Economics and Business, 24(5), 3227-3255.

Johar, G. V., Sengupta, J., \& Aaker, J. (2005). Two roads to updating brand personality impressions; Trait versus evaluative inferencing. Journal of Marketing Research, 42, 458-469.

Kim, M. T. (2015). The roles and relationships of consumer brand relationship and brand performance-related variables. Management \& Information Systems Review, 34(4), 121-139.

Kim, S. Y., Lee, S. H., Lim, T. S. (2014). The effect of self-brand image congruity and functional congruity on brand love, brand attitude and consumers' responses. Journal of Marketing Studies, 22(4), 1-19.

Kramer, R. M. (1999). Trust and distrust in organizations: Emerging perspectives, enduring questions. Annual Review of Psychology, 50, 569-598.

Kressmann, F., Sirgy, M. J., Herrmann, A., Huber, F., Huber, S., \& Lee, D. (2006). Direct and indirect effects of self-image congruence on brand loyalty. Journal of Business Research, 59(9), $955-964$.

Lee, K. S., \& Jung, J. H. (2015). A study on the influence of innovative perception of $\&$ involvement in sports product on hedonic value, product attitude and purchase intention. Korean Journal of Sport Science, 26(2), 292-303.

Loureiro, S. M. C., Ruediger, K. H., \& Demetris, V. (2012). Brand emotional connection and loyalty. Journal of Brand Management, 20(1), 13-27.

Min, D. G., \& Choi, C. J. (2018). The effects of customer's perception of relationship investment efforts on customer loyalty in department service setting: Mediating effect of relationship strength. Korea Research Academy of Distribution and Management Review, 21(1), 57-70.

Ministry of Culture Sports and Tourism. (2018). 2016 Sport white paper.

Ministry of Culture Sports and Tourism. (2018). 2017 Sport Industry White Paper.

Morgan, R. M., \& Hunt, S. D. (1994). The commitment-trust theory of relationship marketing. Journal of Marketing, 58(3), 20-38.

Nunnally, J. C., \& Bernstein, I, H. (1994). Psychometric theory. NY: McGraw-Hill.

Park, H. J. (2015). Antecedents and consequences of brand love for fast fashions. Journal of the Korean Society of Clothing and Textles, 39(5), 728-744.

Park, S. Y. (2015). A study on the influence of brand love on brand loyalty: Focused on smart phone brands. Master's Degree Dissertation, Kyung Hee University.

Rauyruen, P., \& Miller, K. E. (2007). Relationship quality as a predictor of B2B customer loyalty. Journal of Business Research, 60(1), 21-31.

Regan, P. C., Kocan, E. R., \& Whitlock, T. (1998). Ain’t love grand! A prototype analysis of the concept of romantic love. Journal of Social and Personal Relationships, 15, 411-420.

Reichheld, F. P., \& Schefter, P. (2000). E-loyalty: Your secret weapon on the Web. Harvard Business Review, 78, 105-113.

Sirdesmukh, D., Singh, J., \& Sabol, B. (2002), Consumer trust, value, and loyalty in relational exchanges. Journal of Marketing, 66(1), 15-37.

Sirgy, J. M., Grewal, D. T., Mangleburg, F., Park, J. O., Chon, K. S., Claiborne, C. B. (1997). Assessing the predictive validity of two methods of measuring self-image congruence. Journal of the Academy of Marketing Science, 25(3), 229-41.

Sirgy, M. J., \& Su, C. (2000). Destination image, self-congruity, and travel behavior: Toward an integrative model. Journal of Travel Research, 38, 340-352.

Sirgy, M. J., Johar, J. S., Samli, A. C., \& Claiborne, C. B. (1991). Self-congruity versus functional congruity, predictors of consumer behavior. Journal of the Academy of Marketing Science, 19(4), 363-375.

Sirgy, M. J., Rahtz, D., Cicic, M., \& Underwood, R. (2000). A method for assessing residents satisfaction with community-based services: A quality-of life perspective. Social Indicators Research, 49, 279-316.

Trope, Y., \& Liberman, N. (2010). Construal-level theory of psychological distance. Psychology Review, 117(2), 440-463.

Tsiotsou, R. H. (2013). Role of brand relationships and tribal behavior on brand loyalty. American Marketing Association, 
(winter), 366-374.

Yang, Y. I. (2012). The study on the relationships among market orientation, marketing innovation, sustained competitive advantage and performance: From the perspective of CEO. Journal of CEO and Management Studies, 15(1), 115-138.
Yeh, C., Wang, Y., \& Yieh, K. (2016). Predicting smartphone brand loyalty: Consumer value and consumer-brand identification perspectives. International Journal of Information Management, 36(3), 245-257.

\title{
생활체육동호인의 스포츠제품 자아일치성과 제품사랑, 제품신뢰 및 구매행동과의 관계
}

\author{
나채만 \\ 경동대학교, 학과장/조교수
}

〔목적〕 이 연구의 목적은 생활체육동호인의 스포츠제품 자아일치성과 제품사랑, 제품신뢰 및 구매행동과의 관계를 구조방정식모형을 통해 실증적으로 분석하는 데 있다. 〔방법〕 이를 위해 수도권에 소재한 MTB, 테니 스, 배드민턴, 골프 동호회 8곳 회원 중 20세 이상의 남녀 227명을 대상으로 설문조사를 실시하였다. 표집방 법은 편의표본추출법과 설문지작성은 자기기입식으로 하였다. 제안한 구조모형을 검증하기 위해 IBM SPSSWIN Ver. 21.0과 AMOS 18.0을 사용하였다.〔결과〕 첫째, 실제적자아일치성은 제품사랑에 긍정적 인 영향을 미쳤다. 둘째, 이상적자아일치성은 제품사랑에 긍정적인 영향을 미치지 않았다. 셋째, 사회적자아일 치성은 제품사랑에 긍정적인 영향을 미쳤다. 넷째, 제품사랑은 제품신뢰에 긍정적인 영향을 미쳤다. 다섯째, 제품신뢰는 긍정적구전에 긍정적인 영향을 미쳤다. 여섯째, 제품신뢰는 재구매의도에 긍정적인 영향을 미쳤 다. 일곱째, 제품신뢰는 태도적충성도에 긍정적인 영향을 미쳤다.

주요어: 실제적 자아일치성, 이상적 자아일치성, 사회적 자아일치성, 제품사랑, 제품신뢰, 긍정적 구전, 재구 매의도, 태도적 충성도 